\title{
Recovery of cohesion in narrative discourse after left-hemisphere stroke
}

\author{
Charles Ellis, PhD; ${ }^{\text {* }}$ John C. Rosenbek, PhD; ${ }^{2}$ Maude R. Rittman, PhD, RN; ${ }^{1}$ Craig A. Boylstein, PhD; ${ }^{1}$ \\ ${ }^{1}$ Department of Veterans Affairs, Rehabilitation Outcomes Research Center, Gainesville, FL; ${ }^{2}$ Department of \\ Communicative Disorders, University of Florida, Gainesville, FL
}

\begin{abstract}
Little is known about the recovery of narrative discourse after stroke. While several studies have analyzed the recovery of language in individuals with aphasia, few known studies exist on the recovery of narrative discourse in stroke survivors, particularly those who have not been diagnosed with aphasia. In this study, we evaluated the cohesiveness of narrative discourse in a cohort of individuals who had suffered a left-hemisphere stroke and had not been diagnosed with expressive language impairment. We analyzed their narrative discourse at 1, 6, and 12 months poststroke. Our findings indicate that, while the mean number of cohesive ties in narrative discourse remained generally constant during the first year poststroke, the percentage correct use of cohesive ties increased significantly during the same time period. These findings suggest that subtle disruptions in expressive language can be present initially in narrative discourse, and recovery from these disruptions can occur naturally over time.
\end{abstract}

Key words: aphasia, cohesion, cohesive markers, cohesive ties, communication, discourse, language, narratives, speech, stroke.

\section{INTRODUCTION}

Language disorders are a particularly devastating outcome of stroke. Aphasia is a language disorder that results from damage to the central nervous system and affects a person's ability to comprehend and formulate language [1]. Aphasia most frequently occurs after a stroke in the dominant language hemisphere. According to Laska et al., in 2001 approximately 21 to 38 percent of all stroke survivors exhibited aphasia following stroke [2]. Deficits of aphasia include reduced auditory comprehension, verbal expression, reading, and writing abilities, with the severity of these deficits ranging from very mild to severe. The consequences for a stroke survivor with aphasia may include social isolation, depression, role reversal, and increased burden on his or her spouse or caregiver [3-6]. Even mild symptoms of aphasia can result in important changes in the survivor's social and personal life. While more than one-third of all stroke survivors present with aphasia, an even greater number of stroke survivors may be hypothesized to suffer some form of minor language disruption that is not identified as aphasia. These minor language deficits are usually not immediately observed by listeners and can go undetected, particularly during very short hospital stays. As a result, optimal language recovery outcomes are not achieved.

Although several studies have evaluated the natural recovery of language, they used standardized measures

Abbreviations: $\mathrm{ANOVA}=$ analysis of variance, $\mathrm{SD}=$ standard deviation, $\mathrm{TBI}=$ traumatic brain injury, VA $=$ Department of Veterans Affairs.

This material was based on work supported by the Department of Veterans Affairs (VA), Health Services Research and Development Service, Nursing Research Initiative (grant 98-183), with partial support from the VA Office of Academic Affairs.

*Address all correspondence to Charles Ellis, PhD; Department of Rehabilitation Sciences, Medical University of South Carolina, College of Health Professions, 151-B Rutledge Avenue, PO Box 250965, Charleston, SC 29425; 843-792-7492; fax: 843792-0710. Email: ellisc@musc.edu

DOI: 10.1682/JRRD.2005.01.0026 
[2,7-11]. In 1986, Wade et al. noted that while only 12 percent of stroke survivors had significant aphasia that was identifiable with standardized measures, 44 percent of stroke survivors and 57 percent of their caregivers thought speech and language abnormalities existed [11]. However, since many of the patients had no evidence of aphasia, the authors presumed that the deficits reflected mild dysarthria. Unfortunately, additional evaluations were not completed for validation of these claims. Further, it is unclear whether these reports included conversation discourse and/or communication attempts in home and community settings. The reason the stroke survivors and caregivers reported a higher incidence of speech and language difficulties is also unclear. However, Wade et al.'s results suggest that standardized measures commonly used in language assessment may be limited in their language disorder identification capabilities, particularly when the disorders are mild. To support this notion, Copland et al., in 2000, reported that minor disruptions in language may go undetected during traditional approaches to language assessment [12]. They noted that standardized measures such as confrontational naming and word list generation are not sensitive to subtle changes in the quality of expressive language. In addition, standardized assessments cannot account for the multiple processes (linguistic and nonlinguistic) that influence language during high-level language tasks such as conversation. Therefore, alternate methods of language assessment should be considered when individuals who sustain mild strokes and have no obvious language problems are evaluated. Thus, in this article, we report findings of a cohesive analysis of narrative discourse in individuals without diagnosed language disorders following left-hemisphere stroke.

Narrative discourse is a skill generally designed to entertain [13]. It is typically oriented around characters and events and conforms to a superstructure that consists of the following elements: setting, complicating action, and resolution [13]. Narrative discourse provides speakers the opportunity to express temporal progression, establish and maintain personal reference, and highlight certain events above others. This facilitates a more natural flow of information that represents normal communication [14]. The assessment of narrative discourse has received notable attention in the speech-language literature. The study of discourse in individuals with compromised brain function offers a method for testing the interaction of the multiple cognitive processes such as attention, memory, and organization that are involved in the production of discourse [15]. More importantly, an analysis of poststroke narrative discourse can provide additional insights into the manner in which cognitive-linguistic processes that are involved in language are affected by stroke.

Narrative discourse typically contains characteristics of cohesion. Cohesion is a semantic concept; it refers to relations of meaning that exist within a passage, spoken or written, and define it as a passage [16]. Glosser notes that discourse cohesion occurs via linguistic devices that index interconnections of multiple segments of the discourse [15]. More specifically, cohesion occurs in narrative discourse via the use of cohesive markers, which are words that direct the listener to information found outside individual sentences [16]. Therefore, cohesion is a semantic relationship between an element in the passage and some other element that is crucial to its interpretation. The cohesive marker creates a tie with the information found outside the sentence and establishes a meaning relationship across sentences within the passage [17]. Van Leer and Turkstra note that ambiguous intersentential meanings occur when the information that completes a marker's meaning is not readily apparent [18]. As a result of such disrupted cohesion, functional communication is compromised and increased listener effort is required for interpretation of the discourse [18]. Prior studies of discourse production have suggested that disrupted cohesion may reflect impaired lexical retrieval rather than impaired intersentential organization [19]. Therefore, lexical retrieval must be considered when we more clearly define the root cause of reduced complete cohesive ties.

Halliday and Hasan proposed a methodology for cohesion analysis and noted that the basic concept employed in analyzing cohesion of a passage is that of the cohesive tie [16]. The tie includes the cohesive element in addition to that which is presupposed by the cohesive element. Five categories of cohesive elements or markers were defined by Halliday and Hasan: reference, substitution, ellipsis, conjunction, and lexical markers or general nouns. Reference consists of personal, demonstrative, and comparative pronouns (e.g., The car belongs to "him"). Substitution is a relation in the wording rather than meaning. Substitutions are alternate words used in the place of a repetition of a particular item (e.g., My pencil is broken. I need a new "one."). Ellipsis is the omission of an item (e.g., Did you hear the local news? No, only the weather.). Conjunctions are cohesive indirectly as they express certain meanings that presuppose the presence of other discourse components (e.g., The game was over at three. "After" the game, we 
went for ice cream.). Lexical markers or general nouns are cohesive by selection of vocabulary (e.g., James ran into the street. The moving car didn't seem to scare the "man.”) [17].

Previous studies of narrative discourse in individuals with aphasia following left-hemisphere stroke suggest that their discourse is reduced in complexity and volume [20-21]. Ulatowksa et al. noted that during self-generated discourse, individuals with aphasia produced less complex language than normal control subjects [20]. This reduction in complexity was characterized by fewer embedded dependent clauses. Bloom et al. evaluated cohesion in a group of individuals with unilateral left- and right-hemisphere brain injury [22]. Results indicated that individuals with left-hemisphere injury demonstrated cohesion that was spared [22]. In contrast, Glosser and Deser reported significant differences in cohesion when comparing individuals who had fluent aphasia following left-hemisphere lesions with normal control subjects [19]. They suggested that disrupted cohesion might reflect impaired lexical retrieval rather than intersentential organization. Despite these limited and contrasting findings, we hypothesize that cohesion or the linkage of meaning among sentences may be influenced following stroke, even in the absence of overt language disorders. Subsequently, this subtle influence on expressive language may reduce a speaker's communicative ability because a decrease in the use of cohesive ties could dramatically alter the meaning and clarity of discourse produced. In addition, speakers may exhibit difficulties in their ability to consistently convey information in a complete, concise, and clear manner.

Van Leer and Turkstra suggest that to objectively quantify the cohesiveness of narrative discourse and determine how well a speaker can maintain meaning across discourse, researchers must evaluate the cohesive adequacy [18]. Liles proposed a method based on Halliday and Hasan's procedure to address cohesive adequacy in discourse [23]. According to the Liles procedure, cohesive ties are classified as complete, incomplete, or erroneous. Only cohesive ties in which the referent is easily found in the preceding text are deemed complete. Further, cohesive ties are judged incomplete when the information is not found in the text and erroneous if the listener is guided to ambiguous information.

Currently, no established standards exist for evaluating cohesive adequacy in the narrative discourse of adults without brain injury. However, studies that included normal control subjects suggest a high rate of cohesive adequacy in participants without brain injury. Coelho evaluated the percentage correct use of complete cohesive ties during a story retelling task in a group of adults with traumatic brain injury (TBI) and a group without brain injury who served as control subjects [24]. He noted that the normal control subjects produced complete ties 94 percent of the time while the adults with TBI produced complete ties 90 percent of the time. In addition, a study of individuals with TBI by Liles et al. included 23 normal control subjects, aged 18 to 22 years, who produced complete cohesive ties at a rate of 98 percent [25]. While significant literature exists regarding the analysis of cohesion in the narrative discourse in adults following TBI [19,24-30], fewer studies have been completed that evaluate the effects of stroke on cohesion in narrative discourse [19,22,31-32].

To date, no known studies exist that evaluate the changes in cohesion following stroke in individuals without diagnosed language impairment. Cohesion analysis provides an alternate method for evaluating the natural changes in language following stroke. Disruptions in the use of cohesive markers can be evaluated over time in individuals who are recovering from a stroke. We used this methodology to evaluate natural recovery of poststroke narrative discourse. Our aim was to evaluate the use of cohesive ties and determine if the consistency and adequacy of the use of ties is influenced by stroke. Our research questions were-

1. Do speakers without diagnosed language disorders demonstrate changes in the use and/or adequacy of cohesive ties in their poststroke narrative discourse?

2. Given that a change in the use and/or adequacy of cohesive ties exists, what is the nature of these changes and how does cohesion vary across time?

\section{METHODS}

\section{Participants}

Data for this project were obtained from a larger study that was designed to evaluate the influences of ethnicity on stroke recovery and caregiving after discharge home. ${ }^{*}$ The stroke recovery study was reviewed and approved by the

\footnotetext{
* Rittman MR. Culturally sensitive models of stroke recovery and caregiving after discharge home. Nursing Research Initiative 98-183-1. Department of Veterans Affairs, Health Services Research and Development Service; 2001.
} 
University of Florida Health Science Center Institutional Review Board and the Department of Veterans Affairs (VA) Subcommittee on Protection of Human Subjects. In the initial study, 120 participants were enrolled, including 44 who identified themselves as white, 42 as Puerto RicanHispanic, and 34 as African American. Hispanic participants primarily spoke Spanish and were excluded from this analysis so the influence of Spanish/English translations on the language assessments would be eliminated. Individuals with right-hemisphere and/or brain stem involvement were excluded from the study. Of the remaining 78 participants for whom imaging data were available, 13 had lefthemisphere stroke. Left-hemisphere stroke was defined as primarily cortical and/or subcortical involvement, excluding right cortical involvement. Participants with subcortical infarcts were included in this analysis because recent studies have concluded that cortical involvement typically coexists with strokes primarily identified as subcortical [33-38]. Therefore, since the cortex is most likely involved following subcortical infarcts, individuals who have experienced a subcortical stroke are likely to experience mild language deficits. Of the remaining 13 potential participants, one had a documented diagnosis of aphasia and was excluded from the study. The final 12 participants were not referred for a language evaluation, diagnosed with aphasia, or generally language impaired.

The age and imaging results (magnetic resonance imaging/computerized tomography) for each participant are included in Table 1. A certified speech-language pathologist reviewed all language samples for evidence of motor speech disorders. Of the 12 participants, 4 exhibited evidence of mild dysarthria; however, their productions were generally intelligible. Despite mild dysarthria, all participants demonstrated use of cohesive ties in their responses. Therefore, their speaking skills were deemed adequate for participation in the study.

\section{Procedures}

Language samples were obtained from qualitative interviews that were completed as part of the larger study of stroke recovery and caregiving after discharge home. Each participant was interviewed at 1, 6, 12, 18, and 24 months poststroke in his or her home. The 18- and 24-month interviews were not analyzed as part of this study. Each semistructured interview included the same questions. All data collectors were trained to minimally interrupt the participants in their attempts to elicit the stroke survivors' accounts of the stroke experience. Therefore, each interview was more likely to contain a representative sample of the participants' typical daily communication in a relaxed setting. Interviews lasted, on average, $45 \mathrm{~min}$; however, they ranged from $30 \mathrm{~min}$ to $2 \mathrm{~h}$. Audio of all interviews was taped. All interviews included descriptions of a typical day in the life of a stroke survivor, in addition to questions regarding the stroke experience. The 12-month interview was designed to capture the typical daily routine as well as to compare the first few months of the recovery process. Data for the language analysis were obtained from answers participants provided to interview questions at 1, 6, and 12 months that centered on their typical day (Appendix, available online only at http://www.rehab.research.va.gov).

To obtain the language samples for analysis in this study, we selected 5-minute samples from each of the three qualitative interviews (1, 6, and 12 months). The 5-minute samples were collected from the participants' responses to the question regarding their typical day. Samples were downloaded into Speech Tools 2.0 Speech Analyzer (SIL International, Dallas, Texas) [39] from the original audiotape of the interviews. Each 5-minute sample included interviewer questions and prompts.

Table 1.

Age and imaging results for study participants.

\begin{tabular}{|c|c|c|}
\hline Subject & Age & Stroke Type* \\
\hline 1 & 73 & Basal ganglia \\
\hline 2 & 68 & $\begin{array}{l}\text { Frontal cortex, periventricular } \\
\text { demyelination }\end{array}$ \\
\hline 3 & 57 & Caudate head $^{\dagger}$ \\
\hline 4 & 60 & Internal capsule \\
\hline 5 & 46 & Thalamus, internal capsule $\neq$ \\
\hline 6 & 54 & $\begin{array}{l}\text { Basal ganglia with extension into } \\
\text { corona radiate }\end{array}$ \\
\hline 7 & 52 & Basal ganglia \\
\hline 8 & 61 & $\begin{array}{l}\text { Posterior parietal, frontoparietal, } \\
\text { parieto-occipital }^{\ddagger}\end{array}$ \\
\hline 9 & 56 & $\begin{array}{l}\text { Watershed distribution, ACA and } \\
\text { MCA }\end{array}$ \\
\hline 10 & 66 & Thalamus \\
\hline 11 & 72 & Caudate head ${ }^{\S}$ \\
\hline 12 & 65 & $\begin{array}{l}\text { ACA distribution, periventricular } \\
\text { white matter changes, encephalomalocia } \\
\text { temporo-occipital region }{ }^{\ddagger}\end{array}$ \\
\hline \multicolumn{3}{|c|}{$\begin{array}{l}{ }^{*} \text { All strokes were left hemisphere. } \\
{ }^{\dagger} \text { Hemorrhage. } \\
{ }^{\dagger} \text { Left. } \\
{ }^{\S} \text { Second lesion in posterior limb of internal capsule. } \\
\text { ACA = anterior cerebral artery, MCA = middle cerebral artery. } \\
\end{array}$} \\
\hline
\end{tabular}




\section{Transcription and Segmentation}

An independent transcriptionist was employed to transcribe the qualitative interviews for the larger study. We reviewed all language samples selected for cohesion analysis and evaluated all words identified as unintelligible by the transcriber. Those words we found unintelligible were excluded from the analysis.

Each language sample was divided into communication units. A communication unit was defined as the shortest allowable independent clause and any related dependent clauses [40]. A communication unit is the equivalent of a simple sentence. Individual communication units were identified primarily by syntax; however, prosodic and semantic features were used when the unit could not be determined entirely by syntax [15]. In instances where the location of coordinating conjunctions such as "and," "but," and "or" was unclear, their prosodic feature determined their final location at the beginning or ending of the communication unit. One-word responses were not considered in the communication unit calculation (i.e., yes/no and other one-word responses). Scoring guidelines for communication units were based on Hunt's procedure [40]. After the communication units were identified, we calculated the total number of communication units for each participant in each interview $(1,6$, and 12 months).

\section{Cohesion Analysis}

Each communication unit was evaluated for cohesive markers. Cohesive markers within three categories (reference, conjunction, and lexical) were identified. Each cohesive marker was circled in the specified transcript. Following identification of cohesive markers, we judged each for the adequacy of its cohesive tie. Cohesive ties were specified as complete, incomplete, or erroneous as defined by the Liles procedure [23]. Cohesive ties were judged complete when the referent could easily be found in the preceding discourse. Incomplete ties were defined as cohesive markers in which the referent could not be identified in the discourse or was not evident in the context. Erroneous ties were judged as such when multiple referents could be identified in the discourse, therefore making the marker ambiguous. The number of ties in each sample and the percentage of complete ties were calculated.

\section{Scoring Reliability}

Interrater reliability for use of cohesive ties and cohesion adequacy was calculated by having a trained rater independently analyze 6 of the 39 narratives (15\% of the total sample). Reliability was calculated as percentage agreement between the two raters based on point-to-point comparison of scoring decisions. Agreement between raters was 92 percent for identification of cohesive markers, 92 percent for classification of cohesive markers, and 95 percent for classification of adequacy of cohesive ties. The agreement between raters across participants for identification of cohesive markers, classification of cohesive markers, and classification of adequacy ranged from 83 to 100 percent.

\section{RESULTS}

\section{Communication Units}

The raw data for each participant are summarized in Table 2. Group mean and standard deviation (SD) is

Table 2.

Communication units, cohesive ties, and percentage correct cohesive ties for each subject at 1, 6, and 12 months poststroke.

\begin{tabular}{|c|c|c|c|c|c|c|c|c|c|}
\hline \multirow{2}{*}{ Subject } & \multicolumn{3}{|c|}{ Communication Units } & \multicolumn{3}{|c|}{ Cohesive Ties } & \multicolumn{3}{|c|}{ Cohesive Ties Correct (\%) } \\
\hline & $1 \mathrm{Mo}$ & $6 \mathrm{Mo}$ & $12 \mathrm{Mo}$ & 1 Mo & $6 \mathrm{Mo}$ & $12 \mathrm{Mo}$ & $1 \mathrm{Mo}$ & $6 \mathrm{Mo}$ & $12 \mathrm{Mo}$ \\
\hline 1 & 65 & 73 & 57 & 89 & 86 & 68 & 88 & 86 & 96 \\
\hline 2 & 76 & 86 & 59 & 105 & 122 & 119 & 86 & 96 & 92 \\
\hline 3 & 29 & 15 & 15 & 35 & 11 & 21 & 97 & 100 & 95 \\
\hline 4 & 59 & 49 & 50 & 88 & 72 & 90 & 100 & 89 & 96 \\
\hline 5 & 48 & 50 & 31 & 78 & 89 & 33 & 91 & 100 & 100 \\
\hline 8 & 42 & 44 & 50 & 57 & 44 & 65 & 80 & 86 & 100 \\
\hline 9 & 59 & 55 & 61 & 121 & 111 & 114 & 86 & 95 & 95 \\
\hline 10 & 45 & 36 & 44 & 52 & 46 & 56 & 85 & 85 & 93 \\
\hline 11 & 47 & 22 & 29 & 55 & 27 & 28 & 100 & 100 & 100 \\
\hline 12 & 56 & 52 & 57 & 88 & 77 & 79 & 86 & 95 & 100 \\
\hline
\end{tabular}


summarized in Table 3 . We completed a repeatedmeasures analysis of variance (ANOVA) to evaluate the total number of communication units produced, with time poststroke (1, 6, and 12 months) as the within-subject factor. No significant differences existed between participants in the total number of communication units produced at the specified times poststroke $\left(F_{2,22}=1.88, p=0.177\right)$.

\section{Cohesion}

Group mean and SD for the total number of cohesive ties and the percentage complete cohesive ties are summarized in Table 3. We used two separate repeated-measures ANOVA to evaluate the total number of cohesive ties and the percentage complete cohesive ties produced, with time poststroke (1, 6, and 12 months) as the within-subject factor. Participants did not exhibit significant differences in the total number of cohesive ties at 1, 6, and 12 months $\left(F_{2,22}=0.789, p=0.467\right)$. Participants exhibited a difference in the percentage complete cohesive ties $\left(F_{2,22}=\right.$ $4.971, p=0.01)$. Post hoc comparisons indicated significant differences between 1 and 12 months ( $p=0.007$ ). Participants had a higher percentage of complete cohesive ties at 12 months compared with 1 month.

Our analysis of the cohesive tie distribution (reference, conjunction, lexical) produced during narrative discourse indicated that the percentage distribution of each type of cohesive tie remained generally constant over time (Figure). These results indicate that while the percentage correct use of cohesive ties changed during the first year poststroke, the distribution of the three types of cohesive ties remained consistent.

Additional analysis of all incomplete or erroneous ties observed at all intervals (1, 6, and 12 months) indicated that 8 percent $(198)$ of all ties produced $(2,635)$ were either incomplete or erroneous (Table 4). The analysis also indicated that 82 percent (163) of all incomplete or erroneous ties at all intervals were of the reference type, while the final 18 percent (35) were lexical. There were no conjunction type errors. Further, 49 percent (98) of all ties

Table 3.

Mean \pm standard deviation for communication units, cohesive ties, and percentage complete cohesive ties at 1, 6, and 12 months poststroke.

\begin{tabular}{lccc}
\hline \multicolumn{1}{c}{ Parameters } & 1 Mo & 6 Mo & 12 Mo \\
\hline Communication Units & $51.0 \pm 12.7$ & $50 \pm 19$ & $45.0 \pm 14.5$ \\
Cohesive Ties & $76.4 \pm 27.8$ & $74.0 \pm 41.5$ & $69.2 \pm 34.7$ \\
Complete Cohesive Ties & $90 \pm 6$ & $93 \pm 6$ & $96 \pm 3$ \\
\hline \hline
\end{tabular}

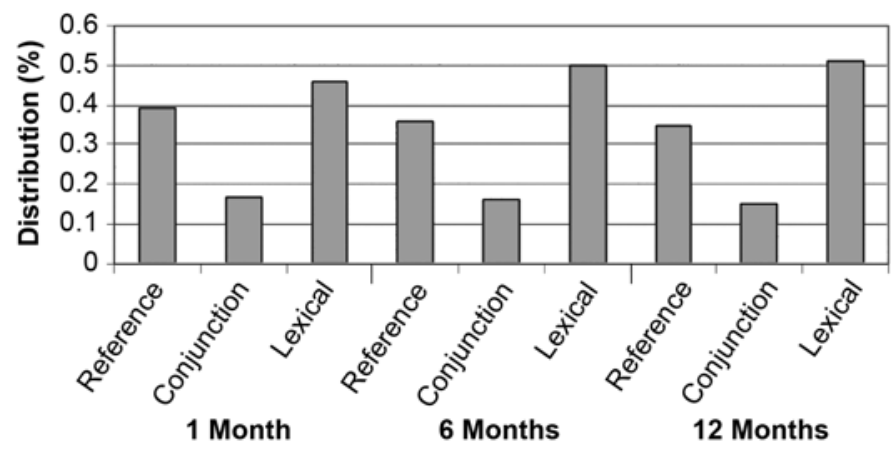

Figure.

Percentage distribution by marker type of all cohesive ties at 1,6 , and 12 months poststroke.

Table 4.

Distribution of cohesive ties.

\begin{tabular}{lc}
\hline \multicolumn{1}{c}{ Cohesive Ties } & No. (\%) \\
\hline Total All Intervals & $2,635(100)$ \\
Total Complete All Intervals & $2,437(92)$ \\
Incomplete or Erroneous & \\
All Intervals & $198(8)$ \\
1 Month & $98(49)$ \\
6 Month & $63(32)$ \\
12 Month & $37(19)$ \\
All Intervals: Reference & $163(82)$ \\
1 Month & $85(87)$ \\
6 Month & $47(75)$ \\
12 Month & $31(84)$ \\
All Intervals: Lexical & $35(18)$ \\
1 Month & $13(13)$ \\
6 Month & $16(25)$ \\
12 Month & $6(16)$ \\
\hline \hline
\end{tabular}

judged either incomplete or erroneous occurred at 1 month, 32 percent (63) occurred at 6 months, and 19 percent (37) occurred at 12 months. Of the 49 percent incomplete or erroneous ties that occurred at 1 month, 87 percent (85) were of the reference type, while 84 percent (31/37) of all incomplete or erroneous ties that occurred at 12 months were also of the reference type.

\section{DISCUSSION}

In this study, we observed that as participants progressed from 1 to 12 months poststroke, a statistically significant percentage point increase in complete cohesive ties was evident. This occurred in the absence of significant changes in the number of communication 
units or total number of cohesive ties produced. Although not statistically significant, we noted a decrease in the total number of communication units produced. This finding was not surprising because our previous, unpublished preliminary data of language recovery after stroke also included decreases in the total number of communication units produced over time [41]. This occurred as the number of words and clauses per communication unit increased. We did not analyze this factor directly in this study because the primary focus was on the adequacy of use of cohesive ties.

A review of all incomplete and erroneous ties revealed that the majority were of the reference type. Reference ties direct the listener to the identity of the thing or things to which the referent refers. The cohesiveness then occurs in the continuity of the specified reference [16]. The method with which these narratives were obtained provided frequent opportunities for participants to use reference ties as they attempted to describe their stroke recovery experience. Particularly, personal pronoun use was evident in all narratives as the participants attempted to describe in detail their poststroke routines. These routines typically included the caregiver, family members, health professionals, neighbors, employers, and others relevant to their recovery. Therefore, attempts by participants to refer to important individuals related to their stroke recovery experience provided them a greater opportunity to use reference ties, as opposed to conjunctions or lexical markers, to specify to whom they were referring. Consequently, personal pronouns such as "he," "she," "him," and "her" were frequently present in their descriptions of a typical day. For example, when participants described a typical day, they might have referred to their son driving them to an appointment with a physician, who was also male. They would state, "He was in the room with me," without specifying whether "he" was the son or the male physician. As a result, exactly whom was being referred to was unclear. Therefore, in instances of high personal pronoun use, the clarity or understanding of the narratives were ultimately decided by the listener's ability to determine to whom these pronouns were referring.

Ulatowska et al. [13] suggest that reference is significantly important to discourse because it connects lower and higher levels of language. Therefore, a disruption in reference words such as pronouns may result in impaired discourse. Further, they note that reference is particularly susceptible to disruption due to the complexity of the reference system. Also, disruptions in reference can result in difficulties developing networks of meaning across utterances. Our participants' use of reference cohesive ties was deemed incomplete or erroneous when we were unable to specifically identify the referent as well as consistently follow referents throughout the interview. Additional investigation of the correlation between reduced reference, cohesive adequacy, and expressive language performance is needed for researchers to determine the impact of reference disruption on communicative ability.

The reason why lexical markers and conjunctions were less susceptible to reduced cohesive adequacy in the narratives is unclear. It may be argued that general nouns and conjunctions create less opportunity for ambiguity compared with pronouns. As a result, lexical markers and conjunctions presented with an increased accuracy of use. General nouns typically refer to person, creature, thing, object, stuff, move, place, and question and are generally limited in the variability of their interpretation. A preliminary review of conjunction use suggests that the participants used conjunctions primarily in an additive ("and," "or," "but”) and temporal (“then,” "next," "after that”) fashion, as opposed to the wider range of functions. These would include use of causal ("so," "consequently," "for that purpose") and adversative conjunctions ("yet," "though," "however"). It is also likely that the task itself dictated greater additive and temporal conjunction use, as a description of a typical day is generally told in a temporal and additive manner.

Finally, we might question whether an increase of 6 percentage points in complete cohesive ties from 1 to 12 months poststroke would account for a functional increase in communicative ability. Further review of the individual percentages of complete cohesive ties indicates that scores ranged from a low of 80 percent at 1 month to a high of 100 percent at 12 months. While we would not expect that all participants would have increased 20 percentage points, we would expect that the observed increase in percentage of complete ties would have some impact on expressive language performance, particularly an improved understanding by listeners who are unfamiliar with the speaker. To date, no established standards exist for percentage correct use of cohesive ties. However, if on average, stroke survivors use cohesive ties incorrectly 10 percent of the time, as observed at 1 month, the listener is left with incomplete information. Therefore, the chance of misinterpretation increases. Subsequently, as the speaker begins to use complete cohesive ties at an accuracy rate closer to 100 percent, overall communication 
improves significantly. Coelho reported that in the study of individuals with TBI, the normal control subjects completed cohesive ties at an average rate of 94 percent [24]. In our 12-month analysis, 9 of the 12 participants exhibited $>94$ percent (range $95 \%-100 \%$ ) cohesive ties, with the final three posting scores of 92 to 93 percent (Table 2). If we use these findings as a guide, our results note an increase in the use of complete ties to a level at 12 months that is similar to rates identified in previous studies for control subjects without brain injury.

Individuals without diagnosed language disorders oftentimes report difficulty with communicative ability in the presence of fluent expressive output. These findings suggest that while they may exhibit fluent output, the cohesiveness of their expressive language may be decreased, thus signaling a less obvious language disruption. Therefore, breakdowns in cohesiveness could potentially disrupt the flow of the output as well as meaning. However, it is unclear if a relationship exists between level of cohesiveness and listener comprehension. As a result, we should not automatically assume that as the cohesiveness of a text, or in this case a narrative, increases, its meaning as interpreted by the listener also increases. Further investigation of these issues is warranted.

\section{CONCLUSIONS}

Little is known about the recovery of narrative discourse after stroke. While several studies have measured the recovery in language in individuals with aphasia, no reported studies of language changes and recovery of individuals without documented language deficits exist. Therefore, the manner in which language is affected following a stroke, particularly in the absence of identified language impairment, is unclear. Reports suggest that even in the presence of normal language scores, many individuals continue to report decreases in language function when compared with their premorbid level. As a result, additional study of the language of individuals without diagnosed poststroke language disorders is warranted.

We realize that language samples obtained during more structured tasks may yield different use and adequacy of cohesive ties. However, our goal was to complete this initial analysis of the cohesiveness of narrative discourse in naturally occurring language output and identify how it is influenced by stroke. Additional studies are needed to fur- ther determine the influences of stroke on the cohesiveness of narrative discourse and the relationship to expressive language performance, particularly in the absence of diagnosed language disorders. Further, the influences of age on discourse abilities must also be considered.

Prior studies of discourse in the elderly have indicated qualitative and quantitative differences relative to younger control subjects [32,42-45]. Stover and Haynes completed a cohesion analysis of conversational discourse and found that older adults (65-90 yr) produced a higher percentage of incomplete ties compared with younger adults (30-59 yr) [45]. In addition, Lock and Armstrong also reported a higher proportion of disrupted cohesion in older adults compared with younger adults [32]. In regards to type of cohesive markers used, North et al. found that older adults ( $\geq 77 \mathrm{yr}$ ) produced a higher proportion of pronouns, more reference ambiguities, and a higher percentage of general nouns [43]. They noted that while the findings of referential ambiguity emerged in some older adults (64-76 yr), they suggest a continuum of referential declination. These findings are of particular importance to future cohesion analyses that include older adults. While our samples appeared generally stable in terms of number of cohesive ties and communication units, the wide age range (46-73 yr) in our participants was not a primary consideration and must be accounted for in future studies.

In conclusion, our ability to more clearly identify the influences of stroke on language will improve our understanding of language disruption and recovery. As a result, we will be able to develop the needed treatments for individuals with subtle disruptions of discourse production who attempt to return to work and/or other social activities.

\section{ACKNOWLEDGMENTS}

We thankfully acknowledge the funding provided by the VA Office of Academic Affairs and Health Services Research and Development Service. We appreciate resources provided by the VA Rehabilitation Outcomes Research Center. We also thank all our participants for their contributions to our research. Dr. Ellis is now with the Department of Rehabilitation Sciences, Medical University of South Carolina, Charleston, South Carolina. 


\section{REFERENCES}

1. Rosenbek JC, LaPointe LL, Wertz RT. Aphasia: A clinical approach. Austin (TX): Pro-Ed; 1989.

2. Laska AC, Hellblom A, Murray V, Kahan T, Von Arbin M. Aphasia in acute stroke and relation to outcome. J Intern Med. 2001;249(5):413-22.

3. Bays CL. Quality of life of stroke survivors: A research synthesis. J Neurosci Nurs. 2001;33(6):310-16.

4. Kauhanen ML, Korpelainen JT, Hiltunen R, Maata R, Mononen H, Brusin E, Sotaniemi KA, Myllyla VV. Aphasia, depression, and non-verbal cognitive impairment in ischaemic stroke. Cerebrovasc Dis. 2000;10(6):455-61.

5. King RB. Quality of life after stroke. Stroke. 1996;27(9): 1467-72.

6. LaPointe LL. Quality of life with aphasia. Semin Speech Lang. 1999;20(1):5-16.

7. Hartman J. Measurement of early spontaneous recovery from aphasia with stroke. Ann Neurol. 1981;9(1):89-91.

8. Lendrem W, Lincoln NB. Spontaneous recovery of language in patients with aphasia between 4 and 34 weeks after stroke. J Neurol Neurosurg Psychiatry. 1985;48(8): 743-48.

9. Lomas J, Kertesz A. Patterns of spontaneous recovery in aphasic groups: A study of adult stroke patients. Brain Lang. 1978;5(3):388-401.

10. Pedersen PM, Vinter K, Olsen TS. Aphasia after stroke: Type, severity and prognosis. The Copenhagen aphasia study. Cerebrovasc Dis. 2004;17(1):35-43.

11. Wade DT, Hewer RL, David RM, Enderby PM. Aphasia after stroke: Natural history and associated deficits. J Neurol Neurosurg Psychiatry. 1986;49(1):11-16.

12. Copland DA, Chenery HJ, Murdoch BE. Persistent deficits in complex language function following dominant nonthalamic subcortical lesions. J Med Speech-Lang Pathol. 2000; $8(1): 1-14$.

13. Ulatowska HK, Allard L, Chapman S. Narrative and procedural discourse in aphasia. In: Joanette Y, Brownell H, editors. Discourse ability and brain damage: Theoretical and impirical perspectives. New York (NY): Springer Verlag; 1990. p. 180-98.

14. Ulatowska HK, Olness GS. Some observations on narratives by aphasics and their contributions to narrative theory. J Narrat Life Hist. 1997;7:259-64.

15. Glosser G. Discourse patterns in neurologically impaired and aged populations. In: Brownell $\mathrm{H}$, Joanette $\mathrm{Y}$, editors. Narrative discourse in neurologically impaired and normal aging adults. San Diego (CA): Singular Publishing Group, Inc; 1993. p. 191-211.

16. Halliday M, Hasan R. Cohesion in English. London (England): Longman Publishing Group; 1976.
17. Coelho CA. Discourse production deficits following traumatic brain injury: A critical review of the recent literature. Aphasiology. 1995;9(5):409-29.

18. Van Leer E, Turkstra L. The effect of elicitation task on discourse coherence and cohesion in adolescents with brain injury. J Commun Disord. 1999;32(5):327-48.

19. Glosser G, Deser T. Patterns of discourse production among neurological patients with fluent language disorders. Brain Lang. 1990;40(1):67-88.

20. Ulatowska HK, North AJ, Macaluso-Hayes S. Production of narrative discourse and procedural discourse in aphasia. Brain Lang. 1981;13(2):345-71.

21. Ulatowska HK, Freedman-Stern R, Doyel AW, MacalusoHaynes S, North AJ. Production of narrative discourse in aphasia. Brain Lang. 1983;19(2):317-34.

22. Bloom RL, Borod JC, Santschi-Haywood C, Pick LH, Obler LK. Left and right hemispheric contributions to discourse coherence and cohesion. Int J Neurosci. 1996:88(1-2): 125-40.

23. Liles BZ. Cohesion in the narratives of normal and language-disordered children. J Speech Hear Res. 1985;28(1): 123-33.

24. Coelho CA. Story narratives of adults with closed head injury and non-brain-injured adults: Influence of socioeconomic status, elicitation task, and executive functioning. J Speech Lang Hear Res. 2002;45(6):1232-48.

25. Liles BZ, Coelho CA, Duffy RJ, Zalagens MR. Effects of elicitation procedures on the narratives of normal and closed head-injured adults. J Speech Hear Disord. 1989; 54(3):356-66.

26. Coelho CA, Liles BZ, Duffy RJ. Discourse analyses with closed head injured adults: Evidence for differing patterns of deficits. Arch Phys Med Rehabil. 1991;72(7):465-68.

27. Hartley LL, Jensen PJ. Three discourse profiles of closedhead-injury speakers: Theoretical and clinical implications. Brain Inj. 1990;6(3):271-82.

28. McDonald S. Pragmatic language skills after closed head injury: Ability to meet the informational needs of the listener. Brain Lang. 1993;44(1):28-46.

29. Mentis M, Prutting CA. Cohesion in the discourse of normal and head-injured adults. J Speech Hear Res. 1987;30(1): 88-98.

30. Davis GA, Coelho CA. Referential cohesion and logical coherence of narration after closed head injury. Brain Lang. 2004;89(3):508-23.

31. Lemme ML, Hedberg NL, Bottenberg DE. Cohesion in the narratives of aphasic adults. In: Brookshire R, editor. Clinical Aphasiology Conference; 1984 May 20-24; Seabrook Island, SC. Minneapolis (MN): BRK Publishers; 1984. p. 215-22.

32. Lock S, Armstrong L. Cohesion analysis of the expository discourse of normal, fluent aphasic and demented adults: A 
JRRD, Volume 42, Number 6, 2005

role in differential diagnosis. Clin Linguist Phon. 1997; 11(4):299-317.

33. Han M, Kang D, Bae H, Oh G, Jeong S, Roh J. Aphasia in striatocapsular infarction may be explained by concomitant small cortical infarctions of cortical language zones [abstract]. Stroke. 2003;34(1):259.

34. Hillis AE, Wityk RJ, Barker PB, Beauchamp NJ, Gailloud P, Murphy K, Cooper O, Metter EJ. Subcortical aphasia and neglect in acute stroke: The role of cortical hypoperfusion. Brain. 2002;125(Pt 5):1094-1104.

35. Hillis AE, Barker PB, Wityk RJ, Aldrich EM, Restrepo L, Breese EL, Work M. Variability in subcortical aphasia is due to variable sites of cortical hypoperfusion. Brain Lang. 2004;89(3):524-30.

36. Nadeau S, Crosson B. Subcortical aphasia. Brain Lang. 1997;58(3):355-402; discussion 418-23.

37. Radanovic M, Scaff M. Speech and language disturbances due to subcortical lesions. Brain Lang. 2003;84(3):337-52.

38. Weiller C, Willmes K, Reiche W, Thron A, Isensee C, Buell V, Ringelstein EB. The case of aphasia or neglect after striatocapsular infarction. Brain. 1993;116(Pt 6):1509-25.

39. Speech Tools 2.0 [CD-ROM]. Dallas (TX): SIL International; 2001.
40. Hunt KW. Grammatical structures written at three grade levels. Champaign (IL): National Council of Teachers of English; 1965.

41. Ellis C, Rosenbek JC, Rittman M. Difference or disorder: An analysis of African American English after stroke [abstract]. In: American Speech-Language-Hearing Association Conference; 2004 Nov 18-20; Philadelphia, PA. Rockville (MD): American Speech-Language-Hearing Association; 2004.

42. Ulatowska HK, Hayashi MM, Cannito MP, Fleming SG. Disruption of reference in aging. Brain Lang. 1986;28(1): 24-41.

43. North AJ, Ulatowska HK, Macaluso-Hayes S. Discourse performance in older adults. Int J Aging Hum Dev. 1986; 23(4):267-83.

44. Mackenzie C. Adult spoken discourse: The influences of age and education. Int J Lang Commun Disord. 2000;35(2): 269-85.

45. Stover SE, Haynes WO. Topic manipulation and cohesive adequacy in conversations of normal adults between ages of 30 and 90. Clin Linguist Phon. 1989;3(2):137-49.

Submitted for publication January 25, 2005. Accepted in revised form August 31, 2005. 